\title{
APOL1 renal risk alleles in patients on chronic hemodialysis in Northwest of Iran
} \author{
Tolouian $^{4}$, Mohammadali Mohajel Shoja ${ }^{5}$, Mohammadreza Ardalan ${ }^{1 *} \mathbb{D}$ \\ ${ }^{1}$ Kidney Research Center, Tabriz University of Medical Sciences, Tabriz, Iran \\ ${ }^{2}$ Maragheh University of Medical Sciences, Maragheh, Iran \\ ${ }^{3}$ Department of Biology, Faculty of Natural Sciences, University of Tabriz, Tabriz, Iran \\ ${ }^{4}$ Division of Nephrology, University of Arizona, Tucson, AZ, USA \\ ${ }^{5}$ Department of Surgery, University of Texas Medical Branch, Galveston, Texas, USA
}

Sepideh Zununi Vahed ${ }^{(\mathbb{1}}$, Ehsan Rikhtegar ${ }^{1}$, Vahideh Ebrahimzadeh Attari $^{2^{(}}$, Mehdi Haghi ${ }^{3}$, Ramin

\section{A R T I C L E I N F O}

\section{Article Type:}

Original

\section{Article History:}

Received: 6 March 2019

Accepted: 13 May 2019

Published online: 9 June 2019

\section{Keywords}

Chronic kidney disease

End-stage renal disease

Hemodialysis

Chronic renal failure

African-American

Apolipoprotein L1

\begin{abstract}
A B S T R A C T
Introduction: Apolipoprotein L1 (APOL1) gene's risk variants located on chromosome 22 are newly discovered factors for the development of chronic renal failure among African-American. These risk alleles were developed on the African continent as an evolutionary defense against sleep sickness due to Trypanosoma brucei rhodesiense and then spread with human migrations.

Objectives: In the present study, we sought to examine these risk variants in a group of hemodialysis patients of Northwest of Iran.

Patients and Methods: Two hundred patients receiving hemodialysis in different centers of the city (Tabriz in Northwest of Iran) were allocated randomly from a total number of 825 patients. The assessment of APOL1 polymorphisms (rs73885319, rs60910145, and rs71785313) was conducted using polymerase chain reaction-restriction fragment length polymorphism (PCR-RFLP) method. Patients' demographic data, history, and their biochemical parameters were recorded based on their last measurement.

Results: No proposed renal risk variants of APOL1 gene in our hemodialysis population were found. All the participants had a wild genotype.

Conclusion: The results of our study match with reports from Europe and Asia. In the paleoanthropological point of view, our results do not support African human migration hypothesis.
\end{abstract}

Implication for health policy/practice/research/medical education:

The appearance of renal risk variants of APOL1 gene (G1, and G2) protect the host against African sleep sleekness; however, predispose carriers to kidney disease. In the present study, we did not find any of these variants in a group of hemodialysis population.

Please cite this paper as: Zununi Vahed S, Rikhtegar E, Ebrahimzadeh V, Haghi M, Tolouian R, Mohajel Shoja M, et al. APOL1 renal risk alleles in patients on chronic hemodialysis in Northwest of Iran. J Renal Inj Prev. 2019; 8(3): 199-203. DOI: 10.15171/ jrip.2019.37.

\section{Introduction}

APOL1, a key apolipoprotein component of high-density lipoprotein (HDL) molecule, is unique to humans and some primates. It has trypanolytic activity and protects them against African trypanosomes. This is one of the solid defense mechanisms against Trypanosoma which causes sleeping sickness (1-4). However, one of the Trypanosoma species (T. brucei rhodesiense) overcomes the lytic effects of APOL1 by expressing a serum resistance-associated (SRA) protein (1). It binds to and inactivates APOL1 in the endosomal and lysosomal compartments, allowing the trypanosomes to proliferate $(5,6)$. This evolutionary burden leads to the emergence of two common humanderived APOL1 variants (G1 and G2) on chromosome 22. These polymorphisms did change the APOL1-SRA binding domain (7) and did restore its trypanosomes lytic activity. APOL1 genetic variants that have lytic activity against T. brucei rhodesiense predispose the host to various type of kidney diseases including focal segmental glomerulosclerosis (FSGS), HIV-associated nephropathy (HIVAN), lupus nephritis, hypertensive nephropathy (HTN), and accelerated progression of diabetic kidney disease (6-8), particularly when allelic frequencies did raise in the population and permitted homozygosity (5). 
End-stage renal diseases (ESRD) is an important public health burden, affecting over half a million people in the United States. Approximately $14 \%$ of Americans with African ancestry carry $2 A P O L 1$ risk alleles that predispose them to develop ESRD at rates 4 to 5 times higher than European-Americans, accounting for the high chronic kidney disease (CKD) burden in this population (6). The appearance of APOL1 renal risk alleles (APOL1-RRV) has had evolutionary origins, selection for protection against T. brucei endemic to sub-Saharan Africa that causes sleeping sickness. However, they are associated with 5-29 times higher odds of severe kidney disease, such as nondiabetic with an impressive odd ration of 16.9 for idiopathic FSGS $(6,9,10)$.

\section{Objectives}

It is needed to explore the differences in APOL1 variability among different races to provide more evidence on future genetic studies on APOL1-related kidney disease. APOL1RRV has impact on innate immunity, vulnerability to CKD and its severity, and the risk of progress to ESRD. The Northwest of Iran was speculated as a gateway for prehistoric human migration toward Russia and Europe. The aim of this study is to assess the prevalence of APOL1RRV in Azarian hemodialysis patients in Northwest of Iran.

\section{Patients and Methods \\ Sample collection}

A total of 200 patients with End Stage Renal Disease (ESRD) on maintenance hemodialysis were recruited from dialysis Units of Imam Reza, Sina, Army and 29 Bahman Hospital at Tabriz from May 2017 to April 2018. The sample size was calculated based on the $12 \%$ prevalence of chronic kidney failure in population (error rate $=0.05$, Power $=80 \%$ ). The total population of East Azerbaijan in Northwest of Iran is approximately estimated around 3.9 million. Close to half of this population lives in Tabriz, which is a metropolitan large city. The total number of patients on chronic hemodialysis treatment in East Azerbaijan is 1,380 , of which 820 of them are receiving chronic hemodialysis in city of Tabriz. Patients with ESRD on chronic hemodialysis who were 18 years of age or older were included in the present study. We excluded subjects with diabetic nephropathy, obstructive nephropathy, and autosomal dominant polycystic kidney disease (ADPKD). Other clinical data including age, gender, weight, height, dialysis vintage, kidney biopsy, if any, the cause of kidney failure, family history of kidney disease and hypertension were collected by chart review or face to face interview.

\section{APOL1 genotyping}

Genomic DNA was extracted from whole blood samples $(5 \mathrm{~mL})$ according to the Samadi Shams et al protocol (11). The APOL1 genotype at the G1 and G2 loci was determined using PCR-restriction fragment length polymorphism (RFLP) method. G1 comprises rs73885319 (Ser342Gly) and rs60910145 (Ile384Met) missense mutations. The G2 variant is characterized by 2 amino acids ( 6 base pair) deletion (N388/Y389) (12, 13). APOL1 high-risk genotypes defined as having 2 risk alleles (G1/G1, G1/G2, or G2/G2) and the low-risk genotypes as having 1 or no risk alleles (G1/G0, G2/ G0, G0/G0). PCR reaction was performed to amplify a fragment (458bp) containing 3 variant sites using $A P O L 1$ forward (5'-AGACGAGCCAGAGCCAATCTTC-3') and reverse (5'- CACCATTGCACTCCAACTTGGC $\left.-3^{\prime}\right)$ primers $(12)$. PCR reactions $(25 \mu \mathrm{L})$ was done in an initial denaturation step (at $94^{\circ} \mathrm{C}$ for 2 minutes) that was followed by 30 steps of denaturation temperatures at $94^{\circ}$ $\mathrm{C}$ for $1 \mathrm{~min}$, annealing at $66^{\circ} \mathrm{C}$ for 1 minute, and extension step at $72^{\circ} \mathrm{C}$ for $1 \mathrm{~min}$, and a final extension step at $72^{\circ} \mathrm{C}$ for 2 minutes. PCR products were run on $1 / 5 \%$ Agarose gel to determine product size. After approval of product size, an independent RFLP test was accomplished for each of the SNPs (Table 1). For each RFLP reaction, PCR product $(2 \mu \mathrm{L})$ was digested with the enzyme (10 units) and the fragments were separated on a $2 \%$ agarose gel.

\section{Ethics issues}

The study was conducted in accordance with Tenets of the Declaration of Helsinki. The present investigation was approved by the committee of clinical research ethics of Tabriz University of Medical Sciences (Ethical code: IRTBZMED.REC.1396.121). The protocol of the study was clarified to all participants and written informed consent was achieved from the patients. This study was extracted from a thesis of residency in internal medicine of Tabriz University of Medical Sciences, Tabriz, Iran (\# 57845).

\section{Statistical analysis}

Data were given as mean \pm SD for normally distributed variables. Median (with maximum and minimum values) was used for non-parametric analysis. Statistical analysis was performed using SPSS statistical software, version 16.0 (SPSS, Chicago, IL). $P<0.05$ was considered significant.

Results

A total of 200 non-diabetic patients (142 men and 58 women) on hemodialysis were included in this study. The patients were on hemodialysis for a median of 36 (minimum: 1, maximum: 264) months. Their mean age

Table 1. Restriction enzymes used in the present study

\begin{tabular}{|c|c|c|}
\hline $\begin{array}{l}\text { APOL1 } \\
\text { genotype }\end{array}$ & SNPs & $\begin{array}{l}\text { Restriction } \\
\text { enzymes }\end{array}$ \\
\hline G1 & $\begin{array}{l}\text { rs73885319 }\left(G 1^{\mathrm{S342G}}\right), A>G \text { Substitution } \\
\text { rs60910145 }\left(G 1^{1384 M}\right), T>G \text { Substitution }\end{array}$ & $\begin{array}{l}\text { HindlII } \\
\text { Nspl }\end{array}$ \\
\hline G2 & rs71785313, 6 bp deletion & MluCl \\
\hline
\end{tabular}


was $56 \pm 16$ years. The causes of ESRD were hypertension in 164 (82\%), glomerulonephritis in 16 (8\%), and unknown in $20(10 \%)$ patients. The mean \pm SD of cholesterol, triglycerides, and HDL-C levels were $149 \pm 40,157 \pm 35$, and $37.5 \pm 12(\mathrm{mg} / \mathrm{dL})$, respectively. The genetic study identified that all of the studied hemodialysis participants were G0 homozygous, neither of them was identified as containing G1 or G2 risk alleles (Figure 1).

\section{Discussion}

Advanced chronic renal failure is a prominent phenotypic presentation/association of APOL1-RRV. We assess the prevalence of this gene in our region. In our study, no APOL1 risk alleles in our sampling group of ESRD patients in Northwestern part of Iran were found. To have higher yield, those patients with diagnosis of diabetic nephropathy, ADPCKD, and obstructive uropathy had excluded. Our findings were compatible with the data from 1000 Genomes projects and other studies indicated that G1 and G2 were not present in any chromosomes of Japanese, Chinese, Indians $(14,15)$, and Europeans $(6,16)$ (Figure 2).

APOL1 gene is unique to humans and some primates and protects them against African trypanosomes. ApoL1 protein lyses trypanosomes mediated by osmotic swelling of parasite lysosomes through a pore-forming mechanism. However, T. brucei rhodesiense produced virulent factor (SRA) that neutralizes APOL1 by binding to its C-terminus. Both $A P O L 1$ risk variants alter the SRA binding amino acid within the C-terminal of APOL1 thus preserving lytic activity $(6,17)$.

The exact mechanism by which $A P O L 1$ variants cause kidney disease remains unknown. Vascular endothelial dysfunction and impaired renal microcirculation have been proposed as potential mechanisms (18). APOL1 is localized in podocytes, proximal tubular epithelial cells, and small-artery endothelium (19-21). APOL1 RRV that produced by these cells may induce cytotoxic damage $(1,22)$. In humans, APOL1 circulates in the blood $(5-\mu \mathrm{g} / \mathrm{mL})$. Its level is not increased with RRV $(19,21)$, but became less bound to HDL and consequently, easily filtrates. A direct toxic effect of filtrated APOL1-RRV on proximal tubular cells and apoptosis of podocytes (22) are another pathogenic possibility (5).

Increased chloride permeability with resultant lysosomal swelling and lysosomal rupture could be another underlying mechanism of the podocyte injury $(1,23)$. In Drosophila model, expression of APOL1-G1 in nephrocytes increased endocytosis of albumin. The same mechanism may create podocytes damage in human (24). APOL1 also transports cations $\left(\mathrm{K}^{+}\right)$across lipid bilayers and APOL1-RRV by decreasing intracellular $\mathrm{K}^{+}$through the aberrant activity of the stress-activated protein kinases, p38 MAPK, and JNK signaling triggers renal cells damage (25). Moreover, APOL1-RRV reduces mitochondrial

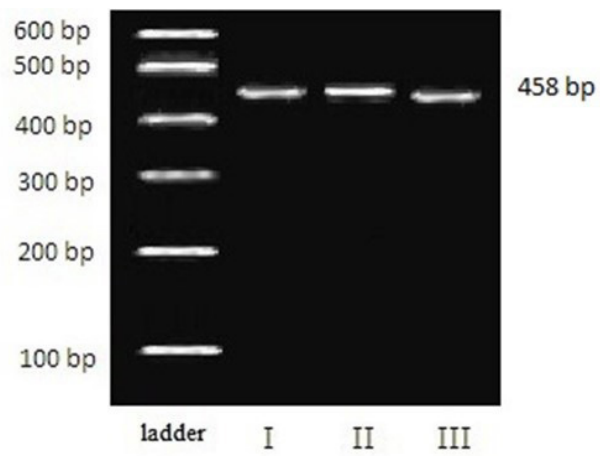

Figure 1. Gel electrophoresis of APOL1 gene polymorphisms. PCRRFLP reaction was performed to amplify and digest a fragment (458bp) containing 3 variants including (I) rs73885319 (Ser342Gly), (II) rs60910145 (Ile384Met), and (III) N388/Y389 using HindIII, Nspl, and $\mathrm{MluCl}$ enzymes.

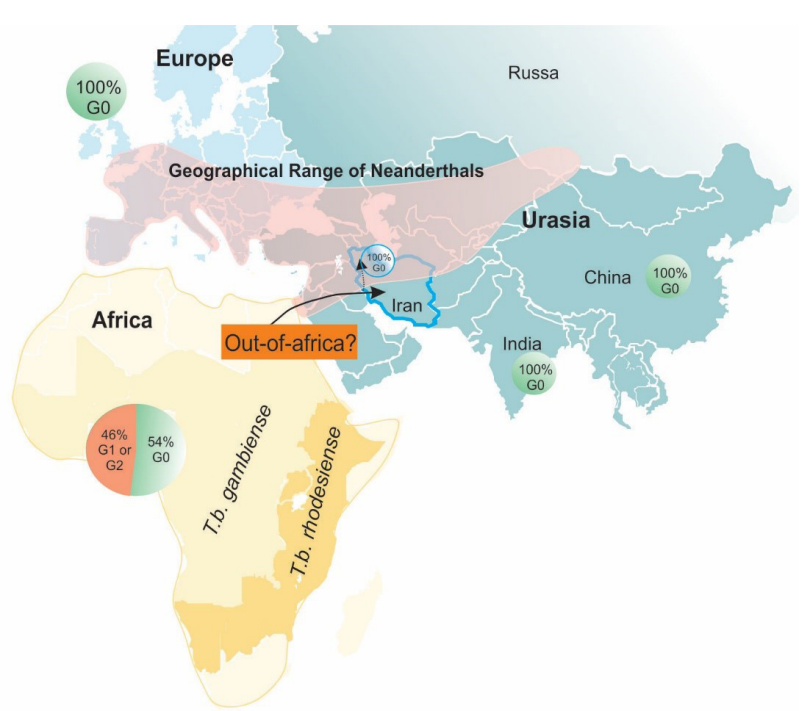

Figure 2. The trace of APOL1-RRV. The association of APOL1, trypanosomiasis, and kidney disease is an evolutionary process of natural selection started in sub- Saharan Africa and led to the appearance of risk variants allele of $A P O L 1$ gene, $\mathrm{G} 1$, and $\mathrm{G} 2$ that protect the host against African sleep sleekness but predispose them to kidney disease. African population carries these alleles while they are absent in Asian. Two possibilities: First, APOL1 risk alleles are emerged in Africa, around 40000 years ago that is after the completion of out of African migration and there was not any risk allele to enter Eurasia. Enduring out of African exceeds, 50-100 thousand years ago. So these risk alleles are not found in Europeans (36), and Asian; Chinese (16), and the present study. Second; because we do not precisely know from when this mutation has developed in sub-Saharan Africa and because of their existence in some primates, it is possible that the out of African trip has never happened and recent population of Eurasia is originated from old settlers of those regions, probably Neanderthals. Neanderthals, the closest evolutionary relatives of present-day humans, lived in large parts of Europe and western Asia before disappearing 30,000 years ago. A draft sequence of the Neanderthal genome extracted from their bones showed that they shared more genetic variants with present-day humans in Eurasia (37)

catalase and superoxide dismutase 2 (SOD2) and predisposes the cell to oxidative damage by reactive oxygen species (ROS) and causes mitochondrial dysfunction (26). Nicotinate phosphoribosyl transferase gene, responsible 
for NAD biosynthesis, is also down-regulated by APOL1RRV (26). The robust associations of APOL1 with HIVAN suggests the inflammation as a trigger that potentiates glomerular injury $(27,28)$. Common inflammatory milieu in HIV acts as a second hit that induces the expression of the APOL1 in macrophages, endothelial, and epithelial cells (28), but interestingly IFN-a does not have any role in this interaction (4).

Approximately $40 \%$ of individuals with two APOL1RRV never develop overt kidney disease $(29,30)$. Individual differences in downstream apoptosis and autophagy signaling (29) and genetically differences in ubiquitin-like protein modifier that destined proteasomal protein degradation are proposed possibilities (31).

Trace of this APOL1-RRV could be helpful in paleoanthropology study and for some theories such as "Out-of-Africa" hypothesis. In paleo-anthropological point of view, our finding probably is not in favor of "Out-of-Africa" or replacement hypotheses that believes "modern humans" evolved only in sub-Saharan Africa, then they spread to Asia and Europe $(32,33)$. This hypothesis has recently come under skepticism by another discipline such as archeological and paleoanthropological evidence. Study of the Early Upper Paleolithic (EUP) tool traditions of Eurasia do not support the arrival of human from sub-Saharan Africa to that region and the findings are more in favor of a continuum of a local succession of tool making traditions (33). It is also suggested that paleoarts objects of EUP era, in Eurasia, attribute to "Neanderthals" (34,35).

\section{Conclusion}

APOL1-RRV emerged in sub-Saharan Africa as a protection against T. brucei rhodesiense but increased the risk of chronic kidney disease. A negative result of our study was similar to other reports from Europe and Asia. In the anthropological point of view, our results do not support African human migration hypothesis.

\section{Study limitations}

Relatively small sample size was a limitation of the present study.

\section{Authors' contribution}

MRA designed the study and selected the cases. ER did sampling and recorded the patients' information. $\mathrm{MH}$ ad VE performed experimental analysis. SZV, RT and MRA performed the interpretation of the data and prepared the manuscript. All authors read and signed the final paper.

\section{Conflicts of interest}

The authors declare no conflict of interest.

Ethical considerations

Ethical issues (including plagiarism, data fabrication, double publication) have been completely observed by the authors

\section{Financial support}

This work was supported by Kidney Research Center of Tabriz University of Medical Sciences, Tabriz, Iran (Grant number: 5/D/489418).

\section{References}

1. Vanhamme L, Paturiaux-Hanocq F, Poelvoorde P, Nolan DP, Lins L, Van Den Abbeele J, et al. Apolipoprotein L-I is the trypanosome lytic factor of human serum. Nature. 2003;422:83-7. doi: 10.1038/nature01461.

2. Lugli EB, Pouliot M, Portela Mdel P, Loomis MR, Raper J. Characterization of primate trypanosome lytic factors. Mol Biochem Parasitol. 2004;138:9-20. doi: 10.1016/j. molbiopara.2004.07.004.

3. Davidson WS, Silva RA, Chantepie S, Lagor WR, Chapman MJ, Kontush A. Proteomic analysis of defined HDL subpopulations reveals particle-specific protein clusters: relevance to antioxidative function. Arterioscler Thromb Vasc Biol. 2009;29:870-6. doi: 10.1161/atvbaha.109.186031.

4. Monajemi H, Fontijn RD, Pannekoek H, Horrevoets AJ. The apolipoprotein L gene cluster has emerged recently in evolution and is expressed in human vascular tissue. Genomics. 2002;79:539-46. doi: 10.1006/geno.2002.6729.

5. Stephens NA, Hajduk SL. Endosomal localization of the serum resistance-associated protein in African trypanosomes confers human infectivity. Eukaryot Cell. 2011;10:1023-33. doi: 10.1128/ec.05112-11.

6. Genovese G, Friedman DJ, Ross MD, Lecordier L, Uzureau P, Freedman BI, et al. Association of trypanolytic ApoL1 variants with kidney disease in African Americans. Science. 2010;329:841-5. doi: 10.1126/science.1193032.

7. Thomson R, Genovese G, Canon C, Kovacsics D, Higgins $\mathrm{MK}$, Carrington $\mathrm{M}$, et al. Evolution of the primate trypanolytic factor APOL1. Proc Natl Acad Sci U S A. 2014;111:E2130-9. doi: 10.1073/pnas.1400699111.

8. Grams ME, Matsushita K, Sang Y, Estrella MM, Foster $\mathrm{MC}$, Tin A, et al. Explaining the racial difference in AKI incidence. J Am Soc Nephrol. 2014;25:1834-41. doi: 10.1681/asn.2013080867.

9. Larsen CP, Beggs ML, Saeed M, Walker PD. Apolipoprotein L1 risk variants associate with systemic lupus erythematosus-associated collapsing glomerulopathy. J Am Soc Nephrol. 2013;24:722-5. doi: 10.1681/asn.2012121180.

10. Kopp JB, Nelson GW, Sampath K, Johnson RC, Genovese $\mathrm{G}$, An P, et al. APOL1 genetic variants in focal segmental glomerulosclerosis and HIV-associated nephropathy. J Am Soc Nephrol. 2011;22:2129-37. doi: 10.1681/ asn.2011040388.

11. Samadi Shams S, Zununi Vahed S, Soltanzad F, Kafil V, Barzegari A, Atashpaz S, et al. Highly effective DNA extraction method from fresh, frozen, dried and clotted blood samples. Bioimpacts. 2011;1:183-7. doi: 10.5681/ bi.2011.025.

12. Cooper A, Ilboudo H, Alibu VP, Ravel S, Enyaru J, Weir $\mathrm{W}$, et al. APOL1 renal risk variants have contrasting resistance and susceptibility associations with African trypanosomiasis. Elife. 2017;6:e25461. doi: 10.7554/ eLife.25461. 
13. O'Seaghdha CM, Parekh RS, Hwang SJ, Li M, Kottgen A, Coresh J, et al. The MYH9/APOL1 region and chronic kidney disease in European-Americans. Hum Mol Genet. 2011;20:2450-6. doi: 10.1093/hmg/ddr118.

14. Yadav AK, Kumar V, Sinha N, Jha V. APOL1 risk allele variants are absent in Indian patients with chronic kidney disease. Kidney Int. 2016;90:906-7. doi: 10.1016/j. kint.2016.07.026.

15. Johnstone DB, Shegokar V, Nihalani D, Rathore YS, Mallik $\mathrm{L}$, Ashish, et al. APOL1 null alleles from a rural village in India do not correlate with glomerulosclerosis. PLoS One. 2012;7:e51546. doi: 10.1371/journal.pone.0051546.

16. Peng T, Wang L, Li G. The analysis of APOL1 genetic variation and haplotype diversity provided by 1000 Genomes project. BMC Nephrol. 2017;18:267. doi: 10.1186/ s12882-017-0675-6.

17. Uzureau P, Uzureau S, Lecordier L, Fontaine F, Tebabi P, Homble F, et al. Mechanism of Trypanosoma brucei gambiense resistance to human serum. Nature. 2013;501:430-4. doi: 10.1038/nature12516.

18. Tin A, Grams ME, Maruthur NM, Astor BC, Couper D, Mosley TH, et al. Hemostatic Factors, APOL1 Risk Variants, and the Risk of ESRD in the Atherosclerosis Risk in Communities Study. Clin J Am Soc Nephrol. 2015;10:78490. doi: 10.2215/cjn.08340814.

19. Madhavan SM, O’Toole JF, Konieczkowski M, Ganesan S, Bruggeman LA, Sedor JR. APOL1 localization in normal kidney and nondiabetic kidney disease. J Am Soc Nephrol. 2011;22:2119-28. doi: 10.1681/asn.2011010069.

20. Ma L, Shelness GS, Snipes JA, Murea M, Antinozzi PA, Cheng D, et al. Localization of APOL1 protein and mRNA in the human kidney: nondiseased tissue, primary cells, and immortalized cell lines. J Am Soc Nephrol. 2015;26:339-48. doi: 10.1681/ASN.2013091017.

21. Bruggeman LA, O'Toole JF, Ross MD, Madhavan SM, Smurzynski M, Wu K, et al. Plasma apolipoprotein L1 levels do not correlate with CKD. J Am Soc Nephrol. 2014;25:63444. doi: 10.1681/asn.2013070700.

22. Candiano G, Musante L, Carraro M, Faccini L, Campanacci L, Zennaro C, et al. Apolipoproteins prevent glomerular albumin permeability induced in vitro by serum from patients with focal segmental glomerulosclerosis. J Am Soc Nephrol. 2001;12:143-50.

23. Lan X, Jhaveri A, Cheng K, Wen H, Saleem MA, Mathieson PW, et al. APOL1 risk variants enhance podocyte necrosis through compromising lysosomal membrane permeability. Am J Physiol Renal Physiol. 2014;307:F326-36. doi: 10.1152/ajprenal.00647.2013.

24. Fu Y, Zhu JY, Richman A, Zhang Y, Xie X, Das JR, et al.
APOL1-G1 in nephrocytes induces hypertrophy and accelerates cell death. J Am Soc Nephrol. 2017;28:1106-16. doi: 10.1681/asn.2016050550.

25. Olabisi OA, Zhang JY, VerPlank L, Zahler N, DiBartolo S, 3rd, Heneghan JF, et al. APOL1 kidney disease risk variants cause cytotoxicity by depleting cellular potassium and inducing stress-activated protein kinases. Proc Natl Acad Sci U S A. 2016;113:830-7. doi: 10.1073/pnas.1522913113.

26. Ma L, Chou JW, Snipes JA, Bharadwaj MS, Craddock $\mathrm{AL}$, Cheng D, et al. APOL1 renal-risk variants induce mitochondrial dysfunction. J Am Soc Nephrol. 2017;28:1093-105. doi: 10.1681/asn.2016050567.

27. Quaggin SE, George AL Jr. Apolipoprotein 11 and the genetic basis for racial disparity in chronic kidney disease. J Am Soc Nephrol.2011;22:1955-8.doi:10.1681/asn.2011090932.

28. Estrella MM, Li M, Tin A, Abraham AG, Shlipak MG, Penugonda S, et al. The association between APOL1 risk alleles and longitudinal kidney function differs by HIV viral suppression status. Clin Infect Dis. 2015;60:646-52. doi: $10.1093 / \mathrm{cid} / \mathrm{ciu} 765$.

29. Chen TK, Choi MJ, Kao WH, Astor BC, Scialla JJ, Appel LJ, et al. Examination of potential modifiers of the association of APOL1 alleles with CKD progression. Clin J Am Soc Nephrol. 2015;10:2128-35. doi: 10.2215/cjn.05220515.

30. Limou S, Nelson GW, Kopp JB, Winkler CA. APOL1 kidney risk alleles: population genetics and disease associations. Adv Chronic Kidney Dis. 2014;21:426-33. doi: 10.1053/j. ackd.2014.06.005.

31. Zhang JY, Wang M, Tian L, Genovese G, Yan P, Wilson JG, et al. UBD modifies APOL1-induced kidney disease risk. Proc Natl Acad Sci U S A. 2018;115:3446-51. doi: 10.1073/ pnas. 1716113115.

32. Sankararaman S, Patterson N, Li H, Paabo S, Reich D. The date of interbreeding between Neandertals and modern humans. PLoS Genet. 2012;8:e1002947. doi: 10.1371/ journal.pgen.1002947.

33. Bednarik RG. The origins of human modernity. Humanities 2012;1:1-103.

34. Bednarik RG. The mythical moderns. Journal of World Prehistory. 2008;21:85-102.

35. Hublin JJ, Spoor F, Braun M, Zonneveld F, Condemi S. A late Neanderthal associated with upper palaeolithic artefacts. Nature. 1996;381:224-6. doi: 10.1038/381224a0

36. Friedman DJ, Pollak MR. Genetics of kidney failure and the evolving story of APOL1. J Clin Invest. 2011;121:3367-74. doi: $10.1172 /$ jci46263

37. Green RE, Krause J, Briggs AW, Maricic T, Stenzel U, Kircher $\mathrm{M}$, et al. A draft sequence of the Neandertal genome. Science. 2010;328:710-22. doi: 10.1126/science.1188021

Copyright ( $\odot 2019$ The Author(s); Published by Nickan Research Institute. This is an open-access article distributed under the terms of the Creative Commons Attribution License (http://creativecommons.org/licenses/by/4.0), which permits unrestricted use, distribution, and reproduction in any medium, provided the original work is properly cited. 